\title{
Asymmetric exchange is associated with $P$ element induced male recombination in Drosophila melanogaster
}

\author{
A Duttaroy \\ Department of Biology, Howard University, Washington DC, 20059, USA
}

\begin{abstract}
Spontaneous meiotic recombination events do not normally occur in the male germ line of Drosophila melanogaster. However, such events are induced in males when a $P$ transposable element or a source of $P$ element encoded transposase protein is present in its genome. This report concerns a molecular analysis of the meiotic exchanges that were induced in the male Drosophila by $\mathrm{P}$ elements within a genetically marked region of the third chromosome. The marked
\end{abstract}

Keywords: Drosophila; P element; recombination; transposable element; genetics

\section{Introduction}

Transposable elements (TEs) are integral components of any genome and may comprise up to $50 \%$ of the entire genome (SanMiguel et al, 1996). Like all other insects, the fruit fly, Drosophila melanogaster's genome harbors a variety of TEs (Adams et al, 2000) including the well-characterized $\mathrm{P}$ transposable element. The $\mathrm{P}$ element is a class of autonomous TE that is found exclusively in the genus Drosophila, and is extremely useful for two reasons: (1) the activity of $\mathrm{P}$ elements, including their mobilization and excision, can be genetically regulated, and (2) P elements are used for obtaining transgenic Drosophila (Rubin and Spradling, 1982). Earlier studies have discovered a variety of syndromes associated with the movement of the P element in the Drosophila genome. These include gonadal sterility, frequent chromosome breakage, and male recombination (Kidwell et al, 1977).

Since spontaneous meiotic recombination events are absent in the male germ line of D. melanogaster, the induction of such exchanges through the presence of $\mathrm{P}$ elements warrants investigation. Previous genetic studies have recognized that $\mathrm{P}$ element-induced male recombination events are legitimate exchange products (McCarron et al, 1989; Duttaroy et al, 1990). Furthermore, induction of male crossing over was found to be possible from a bona fide transposase source, even though the genome is devoid of any other target P element (McCarron

Correspondence: A Duttaroy, PhD, Biology Department, Howard University, 415 College Street NW, Washington, DC 20059, USA.

E-mail: aduttaroy@howard.edu

Received 13 November 2001; accepted 28 April 2002 region also harbors a single $\mathrm{P}$-element called $\mathrm{P}(\mathrm{IArB})$. Fiftysix percent of the $\mathrm{P}(\mathrm{IArB})$ region crossovers indicated some alterations in the $P$ element $5^{\prime}$ fragment. Such alterations appear to be related to asymmetric or unequal genetic exchanges. Finally, $\mathrm{P}(\mathrm{IArB})$ excision was found to be independent of $\mathrm{P}(\mathrm{IArB})$ region crossover events.

Heredity (2002) 89, 114-119. doi:10.1038/sj.hdy.6800108 et al, 1989). The rate of exchange of transposase-initiated crossovers in D. melanogaster males increased when two transposase producers were used. Finally, the crossover distribution of transposase- induced events corresponded with the cytological map of the metaphase chromosome (McCarron et al, 1994). The introduction of a P-element target, with its highly specific transposase binding site, has been shown to produce a marked crossover increase in the P element target region (Sved et al, 1990; Preston and Engels, 1996; Tanaka et al, 1997) as well as a significant increase in regions genetically distinct from the target (Duttaroy et al, 1990; McCarron et al, 1994).

The present report is restricted to the products of crosses involving one $\mathrm{P}$ element target. Crossovers in the $\mathrm{P}(\mathrm{AArB})$ (87C9) and the immediate flanking genomic region are subjected to molecular analysis. Alterations of the $5^{\prime} \mathrm{P}(\mathrm{lArB})$ flanking region are found to be significantly associated with crossovers in the target region while other classes are found to be independent of crossovers in the genomic region immediately flanking the $\mathrm{P}(\mathrm{AArB})$ target. The imprecise nature of transposase mediated crossover events is discussed.

\section{Materials and methods}

\section{Drosophila stocks}

The mutants M(3)76A (Minute76A), Dfd (Deformed), Ace (Acetylcholine esterase), $S b$ (Stubble), and $U b x$ (Ultrabithorax) are the original lethal alleles at these loci: $M(3) 76 A$ and Ace are recessive lethals; $D f d, S b$, and $U b x$ are dominant visible mutations with recessive lethal effect (Lindsley and Zimm, 1992). The construction of the male parent chromosomes $\mathrm{A}$ and $\mathrm{B}$, without the optional $\mathrm{P}(\mathrm{lArB})$ and $\mathrm{P}(\Delta 2-3)$, and the tester female chromosome 
(Figure 1) was described in McCarron et al (1989). Each stock originated from a single third chromosome in the male, balanced and checked by in situ hybridization and southern blot for the presence of $\mathrm{P}$ elements. None were found.

Flies were reared on standard Drosophila cornmealsucrose-yeast medium at $25^{\circ} \mathrm{C}$, the optimum temperature for $\mathrm{P}$ element induced male recombination (Kidwell and Novy, 1979).

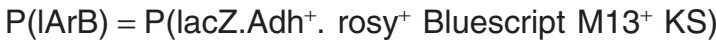

A53.1M3 at $87 \mathrm{C} 9$

$\mathrm{P}(\mathrm{lArB})$ is a homozygous viable $\mathrm{P}$ element insertion with no phenotypic alteration due to the insertion at 87C9. This transposon stock was obtained from the Drosophila stock Center as A53.1M3, which carries the insert in a rosy ${ }^{506}$ background (Bellen et al, 1989). The P(1ArB) location in 87C9 was confirmed by in situ hybridization and Southern blot. The $19 \mathrm{~kb} \mathrm{P}(\mathrm{lArB})$ transposon carries a P-lacZ-hsp70 fusion gene, a $3.2 \mathrm{~kb}$ fragment with the $A d h^{+}$gene, a $7.2 \mathrm{~kb}$ fragment containing the $r y^{+}$gene, and

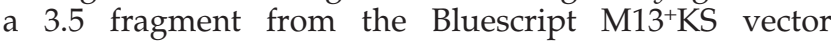
(Stratagene) which carries the gene for ampicillin resistance (Wilson et al, 1989). The original $\mathrm{P}(\mathrm{lArB})$ rosy $^{506}$ chromosome is homozygous viable. Appropriate markers were crossed onto the $r y^{506}$ chromosome to provide the lethal selective system shown in Figure 1, chromosome B.

\section{Molecular techniques}

DNA manipulations were performed according to standard methodology (Sambrook et al, 1989). Genomic DNA was prepared from approximately 125 adult male flies. Probes were prepared either from plasmid DNA or from isolated DNA fragments. For radiolabelling, both $\left[{ }^{32} \mathrm{P}\right] \mathrm{dCTP}$ and $\left[{ }^{32} \mathrm{P}\right] \mathrm{dGTP}$ were used and nick translation was performed with the DNA labelling system obtained from Life Tech.
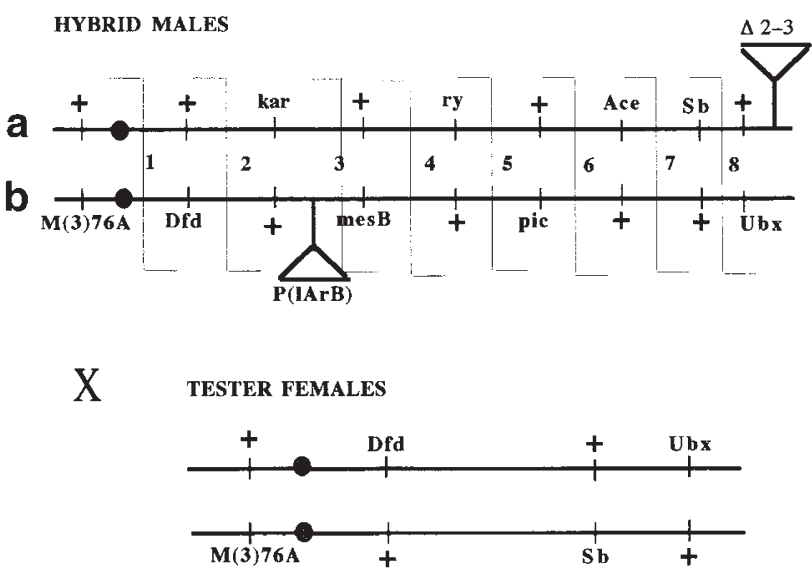

Figure 1 The chromosomes of the hybrid male parent and the tester female are shown with genetic markers delineating the crossover regions, which are numbered. This flanking lethal crossover selective system permits recovery of crossovers between $M(3) 76 \mathrm{~A}$ and $U b x$ in one direction only as shown, due to lethal homozygosity. The transposase source $\mathrm{P}(\Delta 2-3)$, is eliminated after recombination.
Plasmids used

pSall $12.5 \mathrm{~kb}$ Genomic DNA contiguous to the $3^{\prime}$ end of the $\mathrm{P}(\mathrm{AArB})$ insertion was cloned directly using the plasmid rescue method (Wilson et al, 1989). Briefly, DNA from the $\mathrm{P}(\mathrm{AArB})$ A53.M3 stock was digested to completion with the SalI enzyme, ligated in a dilute condition and transformed using E. coli XL1-Blue supercompetent cells (Stratagene, CA). A single clone, carrying $9.0 \mathrm{~kb}$ genomic DNA contiguous to the $3^{\prime}$ end of $\mathrm{P}(\mathrm{lArB})$ insertion (see below) was recovered as a plasmid, which is then designated as pSal12.5.

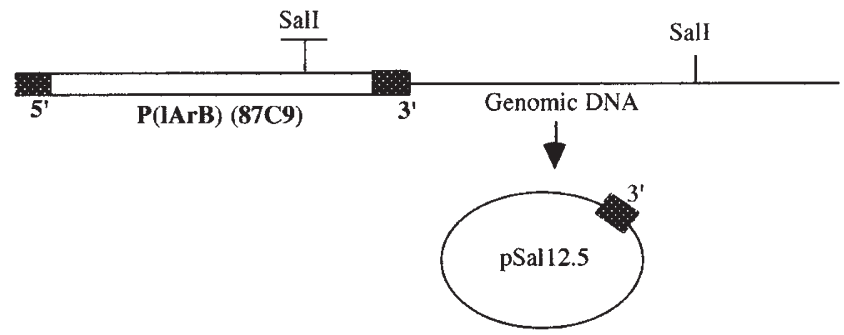

pEcoRI $8.0 \mathrm{~kb}$ (Figure 2a): The $\mathrm{P}(\mathrm{lArB})$ is inserted into an $8.0 \mathrm{~kb}$ EcoRI fragment located in 87C9. This $8.0 \mathrm{~kb}$ EcoRI fragment was isolated from a CantonS genomic library (Maniatis et al, 1978) using the pSal12.5 kb DNA as probe (Benton and Davis, 1977). EcoRI digestion of chromosome A and rosy506 stocks showed an $8.0 \mathrm{~kb}$ band that is intact. Following $\mathrm{P}(\mathrm{AArB})$ insertion in the rosy506 background, the new stock is now designated as A53.1M3.

p $\pi$ 25.7 BWC: The plasmid p $\pi$ 25.7 BWC ('both wings clipped'), is a derivative of the $\mathrm{p} \pi$ 25.7WC plamid (Karess and Rubin, 1984). The P element is missing $39 \mathrm{bp}$ from the $5^{\prime}$ and $23 \mathrm{bp}$ from the $3^{\prime}$ end, and this plasmid carries no other Drosophila genomic sequences.

\section{Results}

\section{Experimental design}

$\mathrm{P}$ element induced meiotic recombination in D. melanogaster males was monitored in the marked regions between $M(3) 76 A$ and $U b x$ on the third chromosome (Figure 1). This investigation measures the distribution as well as the nature of cross over events created when a single $\mathrm{P}$ element called $\mathrm{P}(\mathrm{A} \mathrm{ArB})(87 \mathrm{C} 9)$ is present in the region monitored. Molecular analysis of meiotic crossover events was performed using restriction site differences between the two recombining homologs, chromosomes A and B (Figure 2). $\mathrm{F}_{1}$ hybrid males were obtained as heterozygotes between chromosome A and chromosome B. Chromosome A carries the transposase producer element $\mathrm{P}(\Delta 2-3)(99 B)$ (Robertson et al, 1988), while chromosome $\mathrm{B}$ carries the single $\mathrm{P}$ insertion, $\mathrm{P}(\mathrm{AArB})$ (87C9) in the kar-mesB genetic interval. Transposase-induced recombination events between the $\mathrm{A}$ and $\mathrm{B}$ homologs were analyzed in eight monitored regions from $M(3) 76 \mathrm{~A}$ to $U b x$ (Figure 1). The $F_{1}$ hybrid males $(\mathrm{A} / \mathrm{B})$ were crossed with tester females carrying the same dominant markers as $A$ and $B$. This system selects only those $F_{2}$ progeny that result from crossovers. All other, non- 


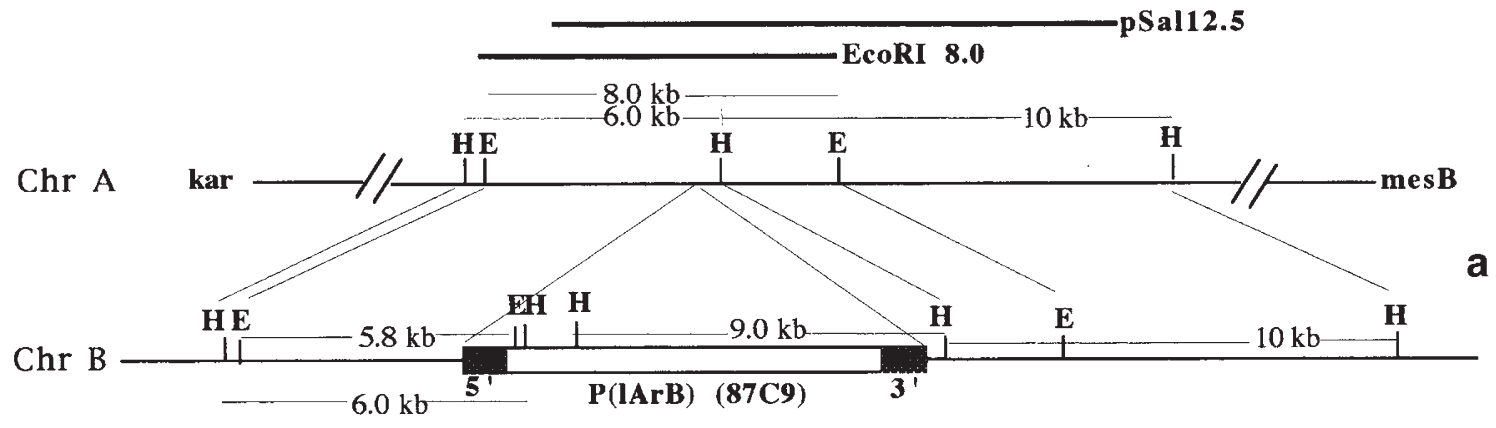

$\underline{5^{\prime}} \mathbf{P}(\mathbf{l A r B})$ recombinant $-1.0 \mathrm{~kb}$

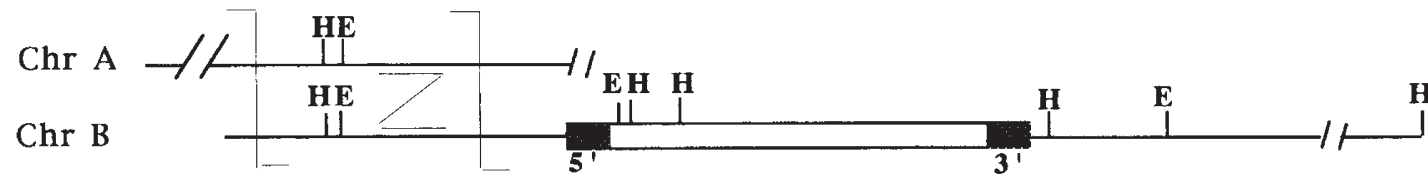

$\underline{3^{\prime} \quad \mathbf{P}(\mathbf{l A r} B) \text { recombinant }}$

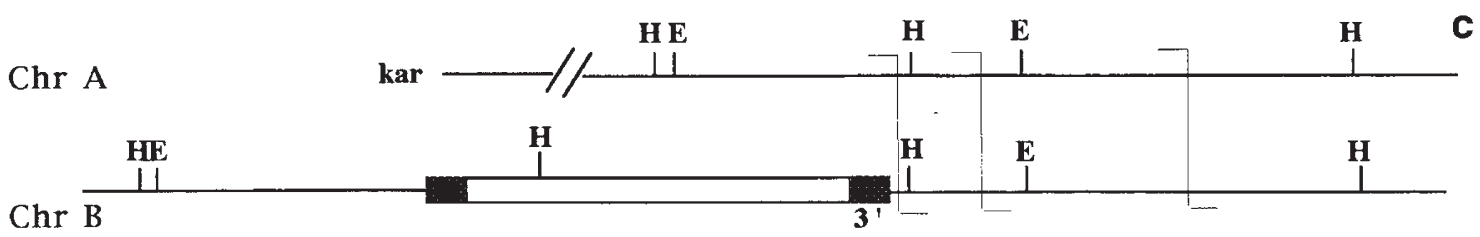

Figure 2 Summary maps of Southern restriction analysis data for the hybrid male parent chromosomes focusing on the region between kar and mesB in Figure 1. Two solid lines at the top designate probes. (a) Restriction map of 87C9 region as found in chromosome A. $\mathrm{P}(\mathrm{lArB})$ insertion took place in chromosome $\mathrm{B}$ in the indicated region. Homologous restriction sites between chromosomes A and B are joined together by thin lines. The $5^{\prime}$ and the $3^{\prime}$ ends of $\mathrm{P}(\mathrm{lArB})$ insert are shown as blank boxes while the rest of the $\mathrm{P}(\mathrm{lArB})$ is shown as open box. (b) Symmetrical recombination events at the $5^{\prime}$ end of $\mathrm{P}(\mathrm{A} \mathrm{ArB})$ will appear like chromosome B, however if recombination events are asymmetric (shown like a Z), the sizes of $5^{\prime} \mathrm{P}(\mathrm{lArB})$ fragments will increase. (c) Symmetrical exchanges at the $3^{\prime}$ end of $\mathrm{P}(\mathrm{lArB})$ should appear like chromosome A.

recombinant, offspring should perish due to homozygosity for one or more dominant marker. Each crossover event recovered includes a portion of the A chromosome to the left of the crossover point and portion of the $B$ chromosome to the right of the crossover point. As previously mentioned, this selective lethal system does not allow the recovery of non-crossovers and, therefore, the two parental chromosomes, as well as crossovers outside the kar-mesB interval are used as controls.

\section{Establishment of molecular markers surrounding the $\mathrm{P}(\mathrm{IArB})(87 \mathrm{C} 9)$ insertion}

The restriction maps of the region immediately surrounding $\mathrm{P}(\mathrm{AArB})(87 \mathrm{C} 9)$ in chromosomes $\mathrm{A}$ and $\mathrm{B}$ are summarized in Figure 2. Three critical fragments in chromosome A are: an $8.0 \mathrm{~kb}$ EcoRI fragment, and two HpaI fragments that are $10.0 \mathrm{~kb}$ and $6.0 \mathrm{~kb}$ in length. The orientations of these three fragments with respect to the flanking genetic markers, kar and mesB are shown in Figure 2. The P(lArB) insertion in chromosome $\mathrm{B}$ has disrupted both the EcoRI $8.0 \mathrm{~kb}$, and the Hpal $6.0 \mathrm{~kb}$ band (Figure 2). The P(1ArB) insertion created the following changes with respect to the distribution of restriction sites: the $8.0 \mathrm{~kb}$ EcoRI fragment in chromosome A was split into a $5.8 \mathrm{~kb}$ band that is located $5^{\prime}$ to the $\mathrm{P}(\mathrm{AArB})$ insertion and $\mathrm{a}>0.0 \mathrm{~kb}$ EcoRI band located $3^{\prime}$ to the $\mathrm{P}(\mathrm{AArB})$. With respect to the $6.0 \mathrm{~kb}$ HpaI fragment in chromosome A, chromosome B fortuitously shows a $6.0 \mathrm{~kb} \mathrm{HpaI}$ band that is located $5^{\prime}$ to the $\mathrm{P}(\mathrm{lArB})$ and a $9.0 \mathrm{~kb}$ HpaI band located $3^{\prime}$ to the $\mathrm{P}(\mathrm{lArB})$. Southern analysis of chromosome A, ry506, and chromosome B DNA that was digested with HpaI and probed with the $\mathrm{P}$ element probe $(\mathrm{p} \pi 25.7 \mathrm{BWC})$, showed no bands in the chromosome A and ry506 lanes, establishing the fact that no other $\mathrm{P}$ homologous sequence is present in these genomes. Chromosome B, on the other hand, showed two bands that are $6.0 \mathrm{~kb}$ and $9.0 \mathrm{~kb}$ in length (Figures 2 and 3). When this blot was probed with the EcoRI $8.0 \mathrm{~kb}$ probe, it picked up two bands in the chromosome $\mathrm{A}$ and in the ry506 control line. The EcoRI 8.0 $\mathrm{kb}$ probe picked up three bands in chromosome $\mathrm{B}$, of which the 10.0 and $6.0 \mathrm{~kb}$ bands were already expected as coming from $\mathrm{A}$ and $\mathrm{B}$, whereas the $9.0 \mathrm{~kb}$ HpaI band was found in chromosome $\mathrm{B}$ only because of $\mathrm{P}(\mathrm{AArB})$ (Figures 2 and 3). The orientations of these genomic fragments were determined with a $\mathrm{P}(\mathrm{lArB}) 5^{\prime}$ specific probe, moreover with the help of several genomic deletions (data not shown).

DNA restriction and crossover diagnostics: Figure 2 shows restriction fragments that are useful in assessing alterations in the $\mathrm{P}(\mathrm{lArB})(87 \mathrm{C} 9)$ region. DNA samples 


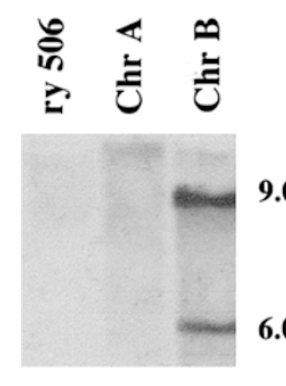

a

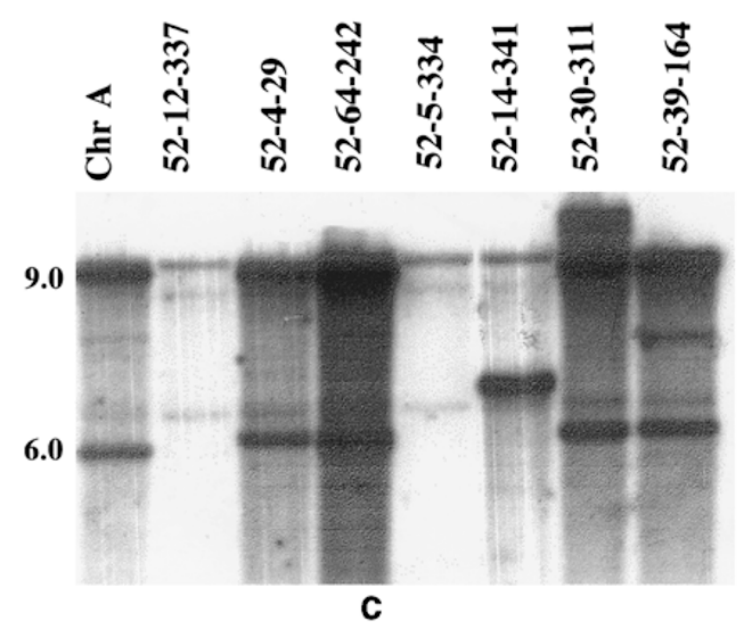

Figure 3 (a) p $\pi 25.7 B W C$ probe picked up no bands in the ry506 and chromosome A controls while two bands, $9.0 \mathrm{~kb}$ and $6.0 \mathrm{~kb}$ long, are seen in chromosome B. The genomic DNA in all three cases was digested with HpaI. (b) HpaI digested DNA from ry506, chromosome A and chromosome B probed with EcoRI $8.0 \mathrm{~kb}$ probe showed a $6.0 \mathrm{~kb}$ and a $10 \mathrm{~kb} \mathrm{HpaI}$ band in ry506 and chromosome A, while in chromosome B an additional $9.0 \mathrm{~kb}$ band was found. (c) $5^{\prime} \mathrm{P}(\mathrm{lArB})$ recombinants. HpaI digested samples probed with $\mathrm{p} \pi 25.7 \mathrm{BWC}$ probe. The $9.0 \mathrm{~kb} \mathrm{HpaI}$ band from the $3^{\prime} \mathrm{P}(\mathrm{larB})$ remains unaltered in all of these recombinants. The $6.0 \mathrm{~kb}$ band from the $5^{\prime} \mathrm{P}(\mathrm{larB})$ end however is altered in each one of these recombinants. Recombinant 52-12-337 and 52-5-334 showed no probable $5^{\prime} \mathrm{P}(\mathrm{lArB})$ region, suggesting partial excision of $5^{\prime} \mathrm{P}$ end that might have happened secondary to recombination event. Lane 52-030-311 shows multiple events in addition to asymmetric exchange at the $5^{\prime}$ end.

were restricted with EcoRI, or HpaI restriction enzymes. The most frequently used series of probes were the following: (1) p $\pi 25.7$ (BWC), (2) the pEcoRI $8.0 \mathrm{~kb}$ clone and (3) the pSalI12.5 $\mathrm{kb}$ clone. The finding, or the absence of certain fragments with specific probes is diagnostic of crossover points as listed below:

(a) 5' $\mathrm{P}(\mathrm{IArB})$ recombinants: Recombination events that happen $5^{\prime}$ to the $\mathrm{P}(\mathrm{AArB})$ insertion should appear like the parental chromosome $\mathrm{B}$ when symmetrical genetic exchanges happen between A and B (Figure 2b). However, if the exchange events are asymmetric then the length of $6.0 \mathrm{~kb} \mathrm{HpaI}$ band will be increased. Several examples of $5^{\prime} \mathrm{P}(\mathrm{lArB})$ alterations are shown in Figure 3c. In recombinants 52-4-29 and 52-64-242 the size of the $6.0 \mathrm{~kb} \mathrm{HpaI}$ band is increased slightly to about $6.2 \mathrm{~kb}$ (Figure 3c). A more dramatic change was noticed in recombinant 52-14-341 where the $6.0 \mathrm{~kb}$ HpaI band becomes $7.0 \mathrm{~kb}$ (Figure 3c). Finally, in two other recombi- nants, 52-12-337 and 52-5-334, the $6.0 \mathrm{~kb}$ HpaI band was lost altogether (Figure $3 \mathrm{c}$ ). The recombination event in each of these cases was associated with the partial excision of the $\mathrm{P}$ element $5^{\prime}$ end.

Alteration in the $\mathrm{P}(\mathrm{lArB}) 5^{\prime}$ flanking regions are most often size increases of 100 to $300 \mathrm{bp}$ in the HpaI $6.0 \mathrm{~kb}$ fragment. Larger size increases and some size decreases also occur, as well as loss of the $5^{\prime}$ fragment, while the $3^{\prime}$ fragment is retained. Since exchanges only occurred at the $5^{\prime}$ end of $\mathrm{P}(\mathrm{lArB})$ insertion, no changes were noticed with respect to the $9.0 \mathrm{~kb} \mathrm{HpaI} \mathrm{band,} \mathrm{which} \mathrm{is} \mathrm{located} \mathrm{3'}$ to the $\mathrm{P}(\mathrm{AArB})$ insertion (Figure $3 \mathrm{c}$ ). In total, 23 out of 53 $\mathrm{P}(\mathrm{A} \mathrm{ArB})$ region crossovers and one of 13 controls showed alterations in the $5^{\prime}$ fragment (Table 1 ). A comparison of these two groups finds them to be significantly different $(P<0.01)$.

(b) 3' $\mathrm{P}(\mathrm{IArB})$ recombinants: In this case, symmetrical exchange products should appear like chromosome A (Figure 2c) and any asymmetric exchange event should appear different. The status of the $8.0 \mathrm{~kb}$ EcoRI band was checked in these recombinants (Figure 2). The $8.0 \mathrm{~kb}$ EcoRI band has altered in two recombinants, 7E4 and 67D1, out of the 10 shown in Figure 4a. Upon probing this blot with the pSal12.5 kb probe it was further confirmed that the $3^{\prime}$ fragment has changed in these two recombinants only (Figure $4 \mathrm{~b}$ ). Among all the $\mathrm{P}(\mathrm{lArB}) 3^{\prime}$ region crossovers, 16 of 53 showed $3^{\prime}$ fragment alterations (Table 1). Among the controls, three of 13 showed such $3^{\prime}$ fragment alterations. A comparison of the two groups shows $P>0.05$, suggesting that $3^{\prime}$ alterations are independent of the $\mathrm{P}(\mathrm{lArB})$ region crossovers.

(c) Other events: P element-transposase interactions are known to cause multiple events such as the complete or partial loss of $\mathrm{P}$ element, inversion, genomic duplication, etc. This study also has seen similar kinds of events, as depicted in Figure 3c.

(d) $\mathrm{P}(\mathrm{IArB})$ inversions-in-place: In three of the $53 \mathrm{P}(\mathrm{AArB})$ region crossovers, $\mathrm{P}(\mathrm{lArB})$ was found to be inverted (Table 1). No inversion was found among the 13 controls. There is no significant difference between the rates for these two groups.

(e) Secondary inserts: Among the $\mathrm{P}(\mathrm{lArB})$ region crossovers, 10 out of 53 show evidence of secondary insertions in 87C (Table1). Among the controls seven out of 13 showed secondary inserts. There is no significant difference between these groups.

\section{Discussion}

The crossover-related $5^{\prime}$ flanking region perturbations, largely consisting of 100 to $300 \mathrm{bp}$ increases, indicate an asymmetry in the exchange event. The $5^{\prime}$ altered fragments in $\mathrm{P}(\mathrm{A} \mathrm{ArB})$ region crossovers bind the same probes as the normal $5^{\prime}$ fragments. These $5^{\prime}$ alterations occur in a limited region, and may result from asymmetric exchanges whose breakpoints are within the Eco RI 8.0 $\mathrm{kb}$ chromosome A sequence and the EcoRI $5.8 \mathrm{~kb}$ chromosome B fragment.

We may assume that such alterations are derived from an initial excision of $\mathrm{P}(\mathrm{A} \mathrm{ArB})$ repaired against a sister 
Table 1 Various $\mathrm{P}(\mathrm{lArB})$ perturbations are associated with male recombination event as seen in kar-masBinterval and their percentages

\begin{tabular}{|c|c|c|c|c|c|}
\hline & \multirow[t]{2}{*}{ Events } & \multicolumn{2}{|c|}{ Test crossovers } & \multicolumn{2}{|c|}{ Control crossover } \\
\hline & & $\begin{array}{l}\text { kar-mesB } \\
\text { crossovers }\end{array}$ & $\begin{array}{l}\% \text { of } \\
\text { total }\end{array}$ & $\begin{array}{l}\text { M(3)76-kar } \\
\text { crossovers }\end{array}$ & $\begin{array}{l}\% \text { of } \\
\text { total }\end{array}$ \\
\hline 1 & Unaltered & 1 & 1.8 & 2 & 15 \\
\hline 2 & $5^{\prime} \mathrm{P}(\mathrm{lArB})$ fragment alteration & 23 & 43.4 & 1 & 8 \\
\hline 3 & $\begin{array}{l}5^{\prime} \mathrm{P}(\mathrm{lArB}) \text { fragment alteration associated with } \\
\mathrm{P}(\mathrm{lArB}) \text { inversion }\end{array}$ & 3 & 5.6 & 0 & 0 \\
\hline 4 & $\begin{array}{l}5^{\prime} \mathrm{P}(\mathrm{lArB}) \text { fragment alteration associated with } \\
\text { secondary insertion }\end{array}$ & 4 & 7.5 & 4 & 30.76 \\
\hline 5 & $3^{\prime} \mathrm{P}(\mathrm{lArB})$ fragment alteration & 16 & 30.2 & 3 & 23 \\
\hline \multirow[t]{2}{*}{6} & $\begin{array}{l}3^{\prime} \mathrm{P}(\mathrm{lArB}) \text { fragment alteration associated with } \\
\mathrm{P}(\mathrm{lArB}) \text { secondary insertion }\end{array}$ & 6 & 11.32 & 3 & 23 \\
\hline & Total & 53 & 100 & 13 & 100 \\
\hline
\end{tabular}
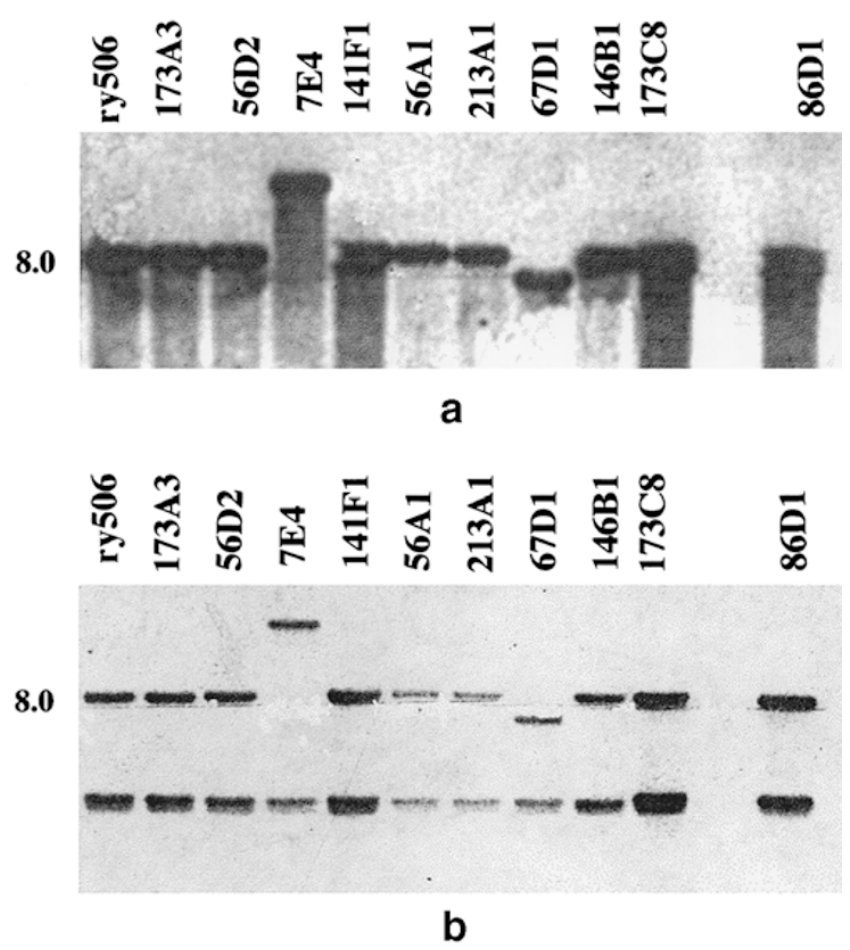

Figure 4 (a) $3^{\prime} \mathrm{P}(\mathrm{lArB})$ recombinants. EcoRI digested DNA is probed with EcoRI $8.0 \mathrm{~kb}$ probe to check the integrity of EcoRI $8.0 \mathrm{~kb}$ band in these recombinants. Recombinant 7E4 and 67D1 show an altered EcoRI band indicating asymmetric exchange, while the EcoRI $8.0 \mathrm{~kb}$ remains the same in rest of the recombinants. (b) A reprobe of the EcoRI digested blot with the pSal $12.5 \mathrm{~kb}$ probe showed similar alterations in the $3^{\prime}$ EcoRI band in recombinants 7E4 and 67D1.

chromatid (Engels et al, 1990). In that case, of the 53 $\mathrm{P}(\mathrm{lArB})$-retaining crossovers in the target region, 26 exchange events were asymmetric at the $5^{\prime}$ end, which would then required some further association with the non-P homologue. In this study, excision events are shown to be independent of the crossover events, as are $\mathrm{P}(\mathrm{lArB})$ retention events. However, since transposase has been shown to induce crossovers in the absence of a Pelement (McCarron et al, 1989, 1994), we need to invoke a prior excision to explain the P-retaining crossovers. The excision process itself is not precise; indeed, precision is rare (Tsubota and Schedl 1986; O'Brochta et al, 1991; Takasu-Ishikawa et al, 1992). Following excisions, remnants of the $\mathrm{P}$ element remain, visible upon sequencing. The basic gap-repair model (Engels et al, 1990; Gloor et $a l, 1991)$ does not predict this. Nonetheless, the independence of transposase in causing double-strand DNA breaks without a P-element present, resulting in crossovers and rearrangements (McCarron et al, 1989, 1994), does predict imprecision in transposase-mediated events. Transposase is capable of acting at multiple sites in the target region, including sites on the non-P-element homologue. Multiple independent actions by transposase on $\mathrm{P}$ and non-P-element homologues may promote the asymmetric crossovers observed. Another mechanism for creating extra DNA sequences at excision sites had been presented by Takasu-Ishikawa et al (1992). Since the extra sequences were not simple remnants but included sequence from the antisense strands, these authors suggest a hairpin model similar to that of Coen and Carpenter (1988) and Coen et al (1989). A third possibility is that the $\mathrm{P}(\mathrm{lArB}) 87 \mathrm{C} 95^{\prime}$ region contains small genomic repeats as yet undetected, whose alternative pairing could produce the 100 to $300 \mathrm{bp}$ increase observed in the $5^{\prime}$ flanking region.

Precision of the exchange event: In an earlier experiment with multiple $\mathrm{P}$ elements, this author noted that the transposase-induced recombinant appears to show symmetrical exchange products (Duttaroy et al, 1990). Among the 24 kar-mes $B$ crossovers in that study, I failed to uncover deleted crossover products identifiable as lethal in heterozygotes with known deletions for this region. Nor could I find evidence of small deletions or duplications in polytene squashes. In the present experiment, utilizing a P element target in the kar-mesB region, I find that, at the level of genomic Southern analysis, asymmetrical exchange events are not only identified, but comprise at least 73\% (39/53) of crossovers. These events occurred with a P-element target present in the kar-mesB region. Several years ago in another experiment, I found no such target in that crossover region (Duttaroy et al, 1990), Therefore, while many unequal crossovers occur in association with the P-element target and are associated with retention of the target in the crossover product, they may not be sufficiently large to involve loss of vital 
genes and consequently may be identifiable only at the molecular level.

\section{Acknowledgement}

The author is indebted to Prof Arthur Chovnick, Dr Margaret McCarron, and Mr Glen Doughty. Fly stocks are obtained from the Drosophila Stock Center in Bloomington, Indiana.

\section{References}

Adams M D et al multiple authors (2000). The genome sequence of Drosophila melanogaster. Science 287: 2185-2195.

Bellen HJ, O'Kane CJ, Wilson C, Grossniklaus U, Pearson RK, Gehring WJ (1989). P-element-mediated enhancer detection: a versatile method to study development in Drosophila. Genes Develop 3: 1288-1300.

Benton WD, Davis RW (1977). Screening gt recombinant clones by hybridization to single plaques in situ. Science 196: 180-182.

Coen ES, Carpenter R (1988). A semi-dominant allele, niv-525, acts in trans to inhibit expression of its wild type homologue in Antirrhinum majus. EMBO J 7: 877-883.

Coen ES, Robbins TP, Almeida J, Hudson A, Carpenter R (1989). Consequences and mechanisms of transposition in Antirrhinum majus, I: Berg DE, Howe MM (eds) Mobile DNA American Society for Microbiology; Washington, DC. pp 413-436.

Duttaroy A, McCarron M, Sitaraman K, Doughty G, Chovnick A (1990). The relationship between $P$ elements and male recombination in Drosophila melanogaster. Genetics 124: 317329.

Engels WR, Johnson-Schlitz DM, Eggleston WB, Sved J (1990). High-frequency $\mathrm{P}$ element loss in Drosophilais homologue dependent. Cell 62: 515-525.

Gloor GB, Nassif NA, Johnson-Schlitz DM, Preston CR, Engels WR (1991). Targeted gene replacement in Drosophila via P element-induced gap repair. Science 253: 1110-1117.

Karess RE, Rubin GM (1984). Analysis of P transposable element functions in Drosophila. Cell 38: 135-146.

Kidwell MG, Kidwell JD, Sved JA (1977). Hybrid dysgenesis in Drosophila melanogaster: a syndrome of aberrant traits including mutation, sterility and male recombination. Genetics 86: 813-833.

Kidwell MG, Novy JB (1979). Hybrid dysgenesis in Drosophila melanogaster: sterility resulting from gonodal dysgenesis in the P-M system. Genetics 92: 1127-1140.

Lindsley DL, Zimm G (1992). The Genome of Drosophila melanogaster. Academic Press: New York.

Maniatis T, Hardinson RC, Lacy E, Lauer J, O'Connel S, Quon
D, Sim GK, Efstradiatis A (1978). The isolation of structural genes from the libraries of eukaryotic DNA. Cell 15: 687-701.

McCarron MY, Duttaroy A, Doughty GA, Chovnick A (1989). P element transposase induces male recombination in Drosophila melanogaster. Genet Res 54: 137-141.

McCarron MY, Duttaroy A, Doughty GA, Chovnick A (1994). Drosophila $\mathrm{P}$ element transposase induces male recombination additively and without a requirement for P element excision or insertion. Genetics 136 : 1013-1023.

O'Brochta DA, Gomez SP, Handler A (1991). P element excision in Drosophila melanogaster and related Drosophilids. Mol Gen Genet 225: 387-394.

Preston CR, Engels WR (1996). P-element induced male recombination and gene conversion in Drosophila. Genetics 144: $1611-1622$.

Robertson HM, Preston CR, Phillis RW, Johnson-Schilitz DM, Benz WK, Engels WR (1988). A stable genomic source of P element transposase in Drosophila melanogaster. Genetics 118 : 461-470.

Rubin GM, Spradling AC (1982). Genetic transformation of Drosophila with transposable element vectors. Science 218 : 348353.

Sambrook J, Fritsch EF, Maniatis T (1989). Molecular Cloning: a laboratory manual, Second edition. Cold Spring Harbor Laboratory: Cold Spring Harbor, New York.

Sanmiguel P, Tikhonov A, Jin YK, Motchoulskaian N, Zakharov D, Melake-Berhan A et al (1996). Nested retrotransposons in the intergenic regions of the maize genome. Science 274: 765-768.

Sved JA, Eggleston WB, Engels WR (1990). Germ-line and somatic recombination induced by in vitro modifid $\mathrm{P}$ elements in Drosophila melanogastor. Genetics 124: 331-337.

Sved JA, Blackman LM, Gilchrist A, Engels WR (1991). High levels of recombination induced by homologous $\mathrm{P}$ elements in Drosophila melanogaster. Mol Gen Genet 225: 443-447.

Tanaka MM, Liang X-M, Gray YHM, Sved JA (1997). The accumulation of P-element induced recombination in the germ line of male Drosophila melanogaster. Genetics 147: 1769-1782.

Takasu-Ishikawa E, Yoshihara M Hotta Y (1992). Extra sequences found at $\mathrm{P}$ element excision sites in Drosophila melanogaster. Mol Gen Genet 232: 17-23.

Tsubota S, Scheldl P (1986). Hybrid dysgensis induced revertants of insertions at the $5^{\prime}$ end of the rudimentary gene in Drosophila melanogaster: transposon-induced control mutations. Genetics 114: 165-185.

Wilson C, Person RK, Bellen H, O'Kane CJ, Grossniklaus U, Gehring WJ (1989). P element-mediated enhancer detection: an efficient method for isolating and chracterizing developmentally regulated genes in Drosophila melanogaster. Genes Dev 3: 1301-1313. 